\title{
Effects of Magnesium on Mechanical Properties of Human Bone
}

\author{
Raviraj Havaldar ${ }^{1}$, S. C. Pilli ${ }^{2}$, B. B. Putti ${ }^{3}$ \\ ${ }^{1}$ Associate Professor, Department of Biomedical Engineering, KLESCET, Belgaum, India. \\ ${ }^{2}$ Principal, KLES College of Engineering and Technology, Belgaum, India. \\ ${ }^{3}$ Professor, Department of Orthopaedics, JNMC, KLE University, Belgaum, India.
}

\begin{abstract}
The human bone is multiphase material consisting of collagenous matrix interspread with mineral crystals. Magnesium participates in the normal formation and remodelling of bone. Magnesium deficiency has been associated with a number of clinical disorders including osteoporosis. The present investigation focuses on quantitative estimation of magnesium, an inorganic constituent of bone and determination of mechanical strength associated with magnesium namely tensile, compression, bending, torsion and shear loads. In particular, this investigation shows that bending strength in human bone is highly dependent on magnesium content of the bone. A correlation is developed to establish relationship between mechanical strength and magnesium composition. The study shows that quantity of magnesium present in the bone and ageing process are interdependent and are highly correlated.
\end{abstract}

Keywords: Bone, magnesium, mechanical strength, ageing process.

\section{Introduction}

Among the components of bone, the mineral phase occupies up to $60 \%$ of the mass or $40 \%$ of the volume of bone. The composition of the mineral phase is mainly calcium and phosphate with a small fraction of carbonates. The quantity of magnesium present in bone is not clear[1]. In addition, the organic matrix occupies about $40 \%$ of the volume of bone. It consists of more than $90 \%$ of Type I collagen and non-collagenous proteins such as osteocalcin, osteonectin, osteopontin which are small in amount, but important in bone structure and bone metabolism. The water phase occupies up to $25 \%$ of the volume of bone[2].

Bone is a multiphase material made up of a tough collagenous matrix intermingled with rigid mineral crystals. The mineral gives bone its stiffness. Without sufficient mineralization, bones will plastically deform under load[3]. Collagen provides toughness to bone making it less brittle so that it has better resistance to fracture. Bone adapts to mechanical stresses largely by changing its size and shape, which are major determinants of its resistance to fracture. Experiments have shown that small additions of bone mineral density caused by mechanical loading can improve bone strength by over $60 \%$ and extend bone fatigue life $[4,5]$.

An increased risk of fractures can be considered to be a consequence of age-related degenerative effects on the skeletal system. Mechanical strength parameter of human bone depends on chemical constituents present in it. Bone mineral provides both rigid support of the animal body and a reservoir of calcium and other elements, of which critical concentrations must be maintained in cells and throughout the body[6]. The criterion for adequate support function is the formation and maintenance of sufficient quantity and quality of bone to support the body throughout life and to withstand ordinary stresses to which skeletal components are subjected[7]. Experiments with rats, mice have assessed bone strength after feeding different levels of calcium. Significant increase in the peak load tolerated was observed at high calcium intakes. Other characteristics, such as stress and stiffness, responded less consistently to dietary calcium in these experiments[8].

Magnesium is involved in about 300 enzymes and plays an important role in the body's metabolism, including muscle tension, the regulation of blood pressure and bone cell function. About $50 \%$ of the body's magnesium can be found in bone, so magnesium is pivotal in mineral and bone homeostasis, bone cell function, growth and hydroxyapatite crystal formation, where it is understood to form a fixed and dynamic pool. This dynamic pool can be seen as a quick exchangeable magnesium store that is able to restore serum magnesium during deficiency. This pool declines during advancing age from $50 \%$ in early adolescence to $33 \%$ in adults to about $10 \%$ in the elderly of the magnesium concentrated in bone. According to Rude[9], in postmenopausal osteoporosis the serum magnesium content decreases. It is also supposed that women, especially those with diagnosed osteoporosis, can benefit from supplementation, although the evidence is not yet conclusive. Ebel and Guenthen[10] has acknowledged the following beneficial effects of magnesium as a basis for health claims: 1) Electrolyte balance, 2) Normal energy-yielding metabolism, 3) Normal muscle function including heart muscle, 4) Normal nerve function, 5) Normal cell division, 6) Maintenance of normal bone, 7) Maintenance of teeth, 8) Normal protein synthesis, 9) Reduction of tiredness and fatigue, 10) Normal psychological functions.

Women with osteoporosis have demonstrated significantly low serum magnesium, evidence of magnesium depletion in magnesium loading test, and low levels of magnesium in bone tissue. Magnesium intake has been positively correlated with forearm bone mineral content in women aged 23-75 years. 
Prospective studies of osteoporotic women given tolerance-dose (up to $750 \mathrm{mg}$ per day) magnesium hydroxide for two years resulted in significant increases in trabecular bone density in the wrist during the first year of the study. In the second year, the bone density measurements simply levelled off. A trial in ovariectomised rats, shown to be a useful model for research relating to postmenopausal women, utilized a highmagnesium, high-calcium diet to evaluate the effect of magnesium on bone strength and bone resorption[11].

Magnesium supplementation at 0.15 percent of the total diet (the equivalent of $1,300 \mathrm{mg}$ magnesium/day in an adult female) increased osteocalcin (a marker for osteoblastic activity), reduced parathyroid hormone and deoxypyridinoline (a bone resorption marker), and increased bone strength and fracture resistance of the femur. Bone formation, prevention of bone resorption, an increase in dynamic strength of bone occurred even though intestinal calcium absorption was reduced in rats on the high magnesium diet[1214].

Magnesium supplementation also appears to have benefit in osteoporosis secondary to malabsorption in gluten-sensitive enteropathy (GSE). In five patients with GSE and osteoporosis of the hip and spine, 500-575 mg magnesium hydroxide daily resulted in statistically significant increases in femoral neck and total proximal femoral bone density. This increase, which took place after two years, occurred along with an increase in erythrocyte magnesium levels[15].

Besides the other major constituents of bone mineral, magnesium may play an important role in biomechanical properties. Magnesium status influences osteocyte proliferation, tissue organisation, and resorption of bone. It may interact directly or indirectly with calcium and phosphor, temper the growth of apatite crystals, interact with hormonal regulators of bone metabolism, and may support functioning of osteoblasts.

Magnesium depleted bones have been described as fragile or osteoporotic or brittle, with thinning of the epiphyseal growth plate, disproportionately wide femur shafts, and abnormal microstructural characteristics $[16,17]$. In this study, the composition of magnesium and mechanical properties of bone for various age groups of both the genders are determined. Age-related changes in magnesium content using Atomic Absorption Spectrometer are quantified. The structural and material level mechanical properties namely: tensile, compression, bending, torsion and shear strengths are quantified through biomechanical tests where experimentations are performed on Instron 3366 Universal Testing Machine, and the effects of magnesium composition on various mechanical properties are determined. The magnesium content and bone strength for various ages in human beings is correlated.

\section{Materials and methods}

Human femur cortical bone specimens were chosen as a source material used in the study. Femur bone is one of the largest and longest among other long bones. Geometrically it is larger and rich in biochemical composition. Femur bone has high bone density and bone mass compared to other long bones of the body. Consequently specimen preparation is easier and greater ranges of the load capabilities of testing could be utilized.

Femur bones studied in this investigation are obtained in a fresh condition. They are harvested from 55 donors, who were non-diseased and non-hospitalised before the death. The specimen samples included both the genders and are in the wide range of age groups $(18-83$ years). Test specimen preparation is carried out immediately after obtaining the sample. The specimen samples are then embalmed and stored in a freezer to store at $-20^{\circ} \mathrm{C}$ wrapped in gauge soaked in phosphate buffered saline solution. Samples are tested with coded labelling to keep the patient information confidential. During all cutting and machining operations, the bone material is frequently and liberally sprayed with saline solution to maintain $\mathrm{pH}$ and to keep it wet. Specimens are prepared according to American Society for Testing and Materials (ASTM) standards.

Mechanical tests are performed on an Instron 3366 table top model Universal Testing Machine and the data is recorded at $50 \mathrm{~Hz}$. The range of the load cell for specimens is $2000 \mathrm{~N}$, with the resolution of $2.0 \mathrm{~N}$. The load applied to the specimen is measured directly by the load cell integral to the testing machine, the corresponding specimen deformation is determined by measuring the displacement of the moving cross-head of the testing machine. As the test specimens had a uniform cross-section, stress and strain are calculated from their original length and diameter measurements.

After specimens are examined for mechanical testings, the same specimens are digested using Aquaregia solution and analysed by Atomic Absorption Spectrophotometer model ELICO SL 168 India, for estimation of magnesium constituent in the respective bone samples. The atomic absorption condition for magnesium is at $285.2 \mathrm{~nm}$.

\section{Results}

Fifty five samples are tested of various age groups ranging from 18 years to 83 years of both the genders. Age groups are divided into four categories; below 30 years, in the range of $31-50$ years, $51-70$ years and above 70 years of age. 
Table 1 : Statistical analysis of mechanical strength of human femur bone of both genders.

\begin{tabular}{|l|r|r|r|r|r|}
\hline Mechanical test & $\leq 30(13)$ & $31-50(13)$ & $51-70(15)$ & $\geq 70(14)$ & $\mathrm{P}$ \\
\hline Tensile strength MPa & $43.44 \pm 3.62$ & $39.82 \pm 4.29$ & $33.16 \pm 6.43$ & $30.16 \pm 7.09$ & $<0.001$ \\
\hline Compressive strength MPa & $155.87 \pm 9.53$ & $142.37 \pm 12.12$ & $124.44 \pm 15.40$ & $115.29 \pm 12.94$ & $<0.001$ \\
\hline Bending strength MPa & $84.03 \pm 9.91$ & $75.22 \pm 11.61$ & $61.89 \pm 10.81$ & $43.57 \pm 11.74$ & $<0.001$ \\
\hline Torsion strength MPa & $40.74 \pm 5.15$ & $35.88 \pm 6.59$ & $29.56 \pm 5.51$ & $21.27 \pm 3.31$ & $<0.001$ \\
\hline Shear strength MPa & $55.41 \pm 4.56$ & $49.54 \pm 7.11$ & $39.61 \pm 8.39$ & $32.62 \pm 8.35$ & $<0.001$ \\
\hline
\end{tabular}

Table 2 : Statistical analysis of magnesium composition of human femur bone of both genders.

\begin{tabular}{|l|r|r|r|r|r|}
\hline Chemical constituent & $\leq 30$ years (13) & $31-50$ years (13) & $51-70$ years $(15)$ & $>70$ years $(14)$ & P value \\
\hline Magnesium (\%) & $0.9 \pm 0.02$ & $0.84 \pm 0.06$ & $0.69 \pm 0.11$ & $0.45 \pm 0.08$ & $<0.001$ \\
\hline
\end{tabular}

Table 3: Correlation analysis of bone magnesium constituent with mechanical strength for both genders.

\begin{tabular}{|l|r|r|r|r|r|}
\hline & Tensile strength & $\begin{array}{r}\text { Compression } \\
\text { strength }\end{array}$ & $\begin{array}{r}\text { Bending } \\
\text { strength }\end{array}$ & Torsion strength & Shear strength \\
\hline Magnesium (\%) & 0.783 & 0.876 & 0.926 & 0.920 & 0.896 \\
\hline P value & $<0.001$ & $<0.001$ & $<0.001$ & $<0.001$ & $<0.001$ \\
\hline
\end{tabular}

Table 1 shows statistical analysis of mechanical strength of femur bone of both male and female for various age groups. Table 2 shows statistical analysis of magnesium composition in percentage for various age groups of both male and female. Specimens are divided into four categories. The first group is of up to 30 years of age, where 13 samples are tested. The mean $\mathrm{Mg}$ content is $0.9 \pm 0.02 \%$. The mean tensile, compressive, bending torsion and shear strength are $43.44 \mathrm{MPa}, 155.87 \mathrm{MPa}, 84.03 \mathrm{MPa}, 40.74 \mathrm{MPa}, 55.41$ respectively. The second group is in the range $31-50$ years of age, where 13 samples are tested. The mean $\mathrm{Mg}$ constituent is found to be $0.84 \pm 0.06 \%$. The mean tensile, compressive, bending torsion and shear strength are $39.82 \mathrm{MPa}$, 142.37 MPa, 75.22 MPa, 35.88 MPa and 49.54 MPa respectively. The third group is in the range of $51-70$ years of age, where 15 samples were examined in this age group. The mean $\mathrm{Mg}$ constituent is found to be $0.69 \pm 0.11 \%$. The mean tensile, compressive, bending torsion and shear strength are $33.16 \mathrm{MPa}, 124.44 \mathrm{MPa}$, 61.89 $\mathrm{MPa}, 29.56 \mathrm{MPa}$ and $39.6 \pm 8.39 \mathrm{MPa}$ respectively. The last group is above 70 years of age, where 14 samples are examined in this category. The average constituent of $\mathrm{Mg}$. is $0.45 \pm 0.08 \%$. The mean tensile, compressive, bending torsion and shear strength are 30.16 MPa, 115.29 $\mathrm{MPa}, 43.57 \mathrm{MPa}, 21.27 \mathrm{MPa}$ and 32.62 $\mathrm{MPa}$ respectively.

In the present study we have obtained the correlation between chemical composition and its mechanical strength. Table 3 shows the correlation between mechanical strength and Mg constituent in bone. There exists the significance of high correlation of 0.926 between $\mathrm{Mg}$ and bending strength where as 0.920 between $\mathrm{Mg}$ and torsion strength. Similarly the correlation factor between $\mathrm{Mg}$ and shear strength is 0.896 where as for $\mathrm{Mg}$ and compressive strength is 0.876 and between $\mathrm{Mg}$ and tensile it is 0.783 , for all $\mathrm{p}$ values lees than 0.001 . This investigation suggests that bending strength in human beings is highly dependent on magnesium content of the bone.

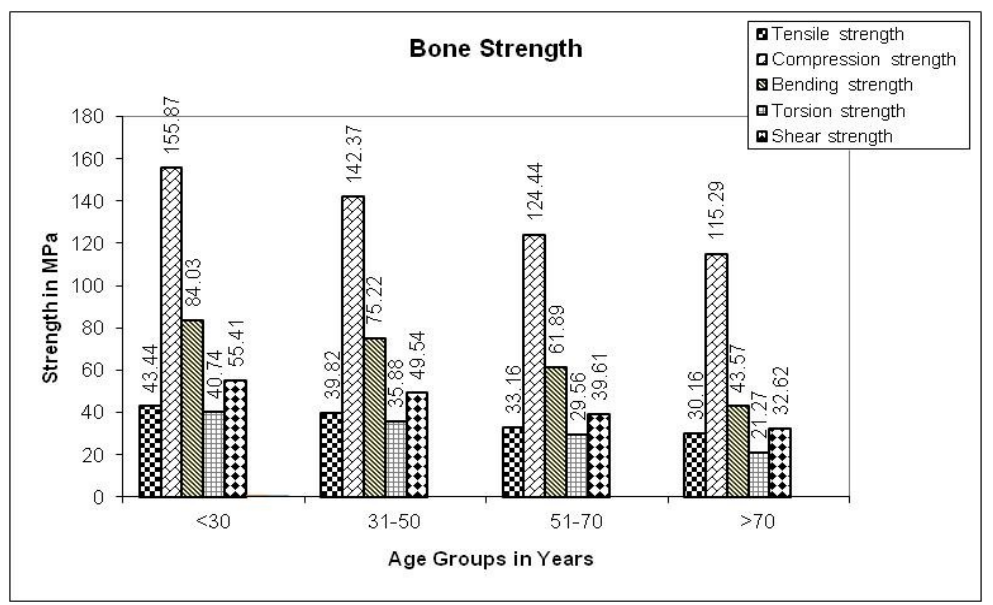

Fig. 1: Tensile, compression, bending, torsion and shear strength for human femur cortical bone of both genders 


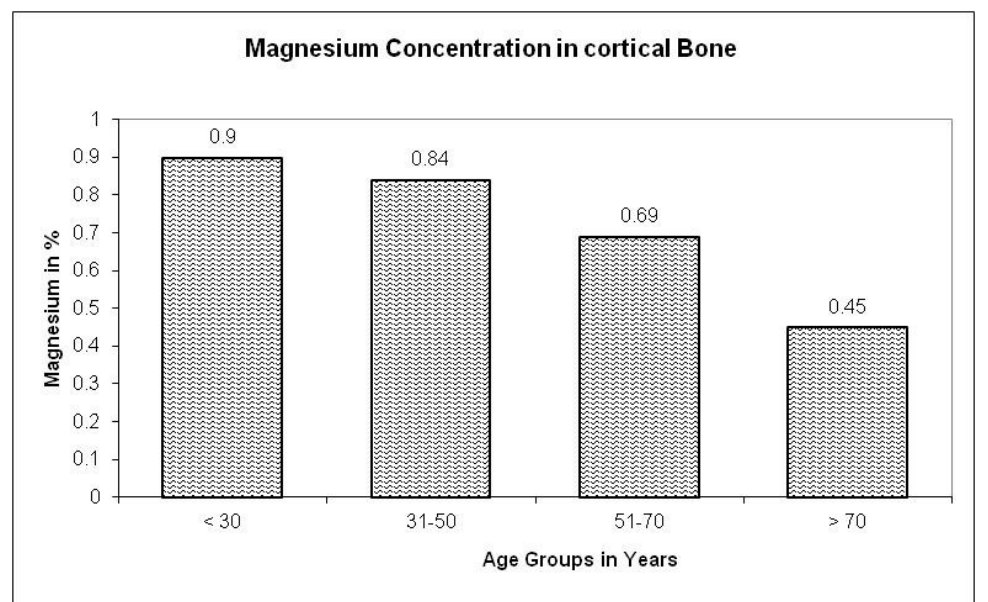

Fig. 2: Magnesium content of human femur cortical bone of both genders

As age advances, a considerable reduction is observed in both mechanical behaviour and magnesium constituent of bone. Fig. 1 and Fig. 2 represent various mechanical properties and quantitative analysis of magnesium concentration of human cortical bone for different age groups. For the age group below thirty, the highest magnesium concentration is recorded and it is $0.9 \%$, for the age group above seventy the magnesium content is observed to be $0.45 \%$, this clearly indicates that magnesium is reduced by $50 \%$ from age below 30 till above 70 years of age. It is also noted that as age advances the reduction in magnesium content is not linear rather it is exponential in reduction. The bone behaves stronger in the age group of below 30 years which has highest of bone strengths than compared with other age groups. Experimental results show tensile strength, compression strength, torsional strength and shear strength decreasing with respect to age. Bending strength reduced nonlinearly resembling the pattern of magnesium. Therefore bending strength is highly dependent on the content of magnesium in human bone.

\section{Discussion}

One of the most dramatic consequences of the aging of the human skeleton is the exponential increase in fracture incidence with age. The experimental procedures used to distribute the test specimen variables of human femur bones indicate the relationship between the age, gender and mechanical strength depends on chemical composition. As we did not observe any trend in fatigue property in the test specimens for any of the age group, this implies that the specimen storage conditions in this programme were successful in maintaining the compact bone material in a mechanically and chemically stabilized state over the wide range of age $[18,19]$.

Ageing is known to increase non-enzymatic cross-linking in the collagen; as this reduces the post yield deformation of the collagen also has been used to explain the age-induced reduction in growth toughness. The results are in agreement with the concept of reduced toughness with increase in age[20].

Age-related non-traumatic fractures are common occurrence and have been predicted with limited success by quantifying bone mass. The present study suggests that investigations of bone quality in terms of its mineral constituents will successfully predict and establish a biomechanical basis for the age-related increase in the incidence of non-traumatic fractures. With respect to the role of ageing, our results show a definitive decrease in the bone mineral composition and the toughness implying that there is an increase in the porosity where interspace area increases with age. This indicates that there is to be expected as more extensive remodelling occurs in older bone to repair damage. Furthermore, based on our observations calcium and phosphor reduces in older age which leads to crack growth. When microcracks are initiated the bone becomes brittle therefore bone strength reduces drastically in the older age[21].

It is believed that the degradation in crack bridging with age is the prominent effect responsible for the age-related deterioration in bone matrix toughness[22]. It is also noted that ageing may result in many additional changes in the structure of bone at much smaller length scales. Thus with increase in age, microdamage increases with lowered collagen quality and quantity. This effect reduces elastic property, toughness of bone and increases non-traumatic fractures[23].

Systemic conditions, particularly those resulting in bone tissue changes, are viewed as important factors for strength predictability[24]. Within this respect, reduction in magnesium content could be considered as a risk factor for osteoporosis, as it is recognized to affect bone metabolism[9].

In the present study, magnesium constituent is estimated and demonstrated with respect to age and gender. Bone turnover is physiologically complex process that involves not only interaction among cells and bone matrix but also a variety of systemic and local regulation factors that coordinate cell proliferation and 
activity[25]. Many studies report that magnesium deficiency is in direct relation with age and has a particular influence on bone mass loss. This effect is observed in both male and female, female show higher bone mass loss when the deficiency is increased than compared to male[9, 26, 27].

Rude et al., [25] show that magnesium deficiency had a negative effect on the peri-implant cortical bone significantly reducing tibial cortical thickness. Changes in cortical thickness greatly influences deformation of the peri-implant bone crest when subjected to occlusal load. By finite element analysis, it was found that low-density cancellous bone and cortical bone thinning are more likely to undergo resorption when compared with bone tissue with thicker cortical and high-density cancellous bone, which could interfere in the treatment predictability. Changes in bone morphology and size of hydroxyapatite crystals, affecting bone architecture, may have occurrence around implants in $\mathrm{Mg}$ group[28]. The uneven configuration of bone structure may cause structural weakness, creating micro fractures of the trabeculae and changing biomechanical behaviour. Such a structural change in hydroxyapatite crystals could not be detected by the related method, because the crystals' affected geometry may be masked under a bone structure with a radiographic density similar to that of the control group $[29,30]$.

An epidemiologic study suggested that a lower magnesium intake was reported in male and female subjects with low Bone Mineral Density (BMD) of the greater trochanter of the proximal femur compared to those with greater $\mathrm{BMD}[31]$. Other findings from human trials and observational studies, although limited, suggest that higher magnesium consumption or supplement use improves skeletal measurements and perhaps reduces fracture risk. It is not established yet whether individuals taking a combination supplement of calcium and vitamin D will have a negative impact on magnesium status[32].

Magnesium activates cellular enzyme activity, allowing the body to convert vitamin D into its active form to help with calcium absorption and bone building. Magnesium leads to the release of the hormone calcitonin, which helps to preserve bone structure and draws calcium out of the blood and soft tissues and back into the bones $[9,33]$.

Magnesium is necessary for energy metabolism and physical performance and new research shows that magnesium increases testosterone levels. Magnesium supports protein synthesis because it enables enzyme function in the body. Additionally, research shows that magnesium supplementation paired with resistance exercise can make bone stronger. Researchers suggest that magnesium plays a role at the ribosomal level in protein synthesis, and taking it while strength training leads to significant strength and muscle mass gains $[10$, $34,35]$.

Several mechanisms may induce bone mass decrease related to magnesium deficiency, such as parathyroid hormone regulation, stimulation of pro-inflammatory cytokines and change in hydroxyapatite crystal formation. An increased release of parathyroid hormone is related to an increase in calcium resorption by the kidneys, an increase in paracellular calcium and magnesium resorption through the stimulation of calcium channels[36]. Thus, bone resorption, as a result of stimulation of new osteoclasts and an increased activity of mature ones, leads to imbalance of bone turnover[37]. A statistically significant difference between groups was found in this study by an assessment of this pathway, with higher values of serum parathyroid hormone concentration for animals with deficiency. An increased release of parathyroid hormone is observed previously in mice with this deficiency, in short periods of reduced mineral intake[9, 38]. Significantly higher values of urine Deoxypyridinoline, an important bone resorption marker, were also verified in the group with magnesium deficiency. These data confirm the increased activity of bone resorption. The bone formation marker is regulated by several calcitropic hormones, parathyroid hormone and glucocorticoids [39]. These findings express an imbalance on bone turnover in animals with magnesium deficiency, showing higher resorption activity without a concomitant increase in bone formation activity. Within the limitations of this study, it is concluded that magnesium deficiency may lead to alterations on systemic bone metabolism and reduction of cortical bone thickness.

Hoffler et. al.,[40] published an extensive study detailing the microhardness of moist human bone lamellae and its variation with age and gender. He tested interstitial tissue of the fibula on surfaces normal to the anatomical axis and found bone microhardness to be dependent of age and gender in skeletally mature adults. The most striking results from the study are that bone mineral and mechanical strength are highly dependent parameters of age and gender. The data demonstrates that bone mineral composition is an effective predictor of hardness of bone.

\section{Conclusion}

A quantitative analysis is performed on human femur cortical bone to estimate the magnesium content. The specimens are subjected for the analysis of various mechanical strengths namely: tensile, compression, bending, torsion and shear strength. The magnesium composition is estimated. A relationship between chemical and mechanical properties of human bone with respect to age of both genders is established. The fracture toughness of cortical bone shows significant deterioration with aging. Magnesium deficiency causes the 
reduction in bone strength. The correlation analysis investigates that bending strength is highly dependent on magnesium content. The results suggest that chemical measures of bone mineral status would supplement the conventional measure of bone strength for improved assessment of fracture risk. In general bone mineral composition and ageing process are interdependent and are highly correlated with the understanding of bone mechanical behaviour.

\section{References}

[1] Agna J. W., Knowles H. C., and Alverson G., The mineral content of normal human bone, J. of Clinical Chemistry, pp. 1357-1360, 1958.

[2] Mbuyi-Muamba J.-M., Dequeker J., and Gevers G., Biochemistry of Bone, Baillieres Clinical Rheumatology, vol. 2, 1988.

[3] Adams M. A., Kerin A. J., and Bhatia L. S., Experimental determination of stress distribution in articular cartilagr before and after sustained loading, J. of Clinical Biomechanics, vol. 14, pp. 88-96, 1999.

[4] Beason D. P., Dakin G. J., Lopez R. R., and Alonso J. E., Bone mineral density correlates with fracture load in experimental side impacts of the pelvis, J. of Biomechanics, vol. 36, pp. 219-227, 2002.

[5] Anderson J. J. B., Calcium, phosphorus and human bone development, J. Nutr., vol. 126, p. 1153S-1158S, 1996.

[6] Ardeshirpour L., Cole D., and Carpenter T., Evaluation of bone and mineral disorders, J. of Pediatric Endocrinology, vol. 5, pp. 584-598, 2007.

[7] Braillon P. M., and Chotel F., Bone mineral content and soft-tissue assessment in limb segments by dual-energy X-ray absorptiometry, J. of Clinical Densitometry, vol. 6, pp. 149-158, 2003.

[8] Dziedzic-Goclawska A., Ostrowski K., and Michalik J., Decrease of the crystallinity of bone mineral in osteopetrotic rats, Metab. Bone Dis. \& Rel. Res., vol. 2, pp. 33-37, 1979

[9] Rude R. K., Singer F. R., and Gruber H. E., Skeletal and hormonal effects of magnesium deficiency, Am J. Clin Nutr, vol. 28, pp. 1312-141, 2009.

[10] Ebel H., and Guenther T., Magnesium metabolism: A review, J. of Clin. Chem. Clin. Biochem. , vol. 18, pp. 257-270, 1980.

[11] Alfrey A. C., Miller N. L., and Trow R., Effect of age and magnesium depletion on bone magnesium pools in rats, J. of Clin. Inv., vol. 54, pp. 1074-1081, 1974.

[12] Gilbert P. U. P. A., Abrecht M., and Frazer B. H., The organic-mineral interface in biominerals, J. Minerology and Geochemistry, vol. 59, pp. 157-185, 2005 .

[13] Digitale E., Hathaway, Heneman K., and Zidenberg-Cherr S., Calcium and osteoporosis, ANR Publications, vol. 8138, pp. 1-5, 1997.

[14] Price T. D., Schoeninger M. J., and Armelagos G. J., Bone chemistry and past behaviour: an overview, J. of Human Evolution, vol. 14, pp. 419-447, 1985 .

[15] Ji B. and Gao H., Mechanical properties of nanostructure of biological materials, J. of Mechanics and Physics of solids, vol. 52, pp. 1963-1990, 2004.

[16] Kramer B. and Shear M. J., Composition of bone, J. Biol. Chem., vol. 29, pp. 147-160, 1928.

[17] Keaveny T. M., Morgan E. F., and Yeh O. C., Bone mechanics, TMH, 2009.

[18] Giesecke J. C., Age at death in the human skeleton: A combined analysis of four phase-based aging systems to determine efficiency and accuracy in multifactorial age range assignments, in geography and anthropology. Southwest Texas State University, 2002.

[19] Akkus O., Adar F., and Schaffler M. B., Age-related changes in physicochemical properties of mineral crystals are related to impaired mechanical function of cortical bone, J. of Bone, vol. 34, pp. 443-453, 2004.

[20] Wang X., Shen X., Li X., and Agarwal C. M., Age-related changes in the collagen network and toughness of bone, J. of Bone, vol. 31, pp. 1-7, 2002.

[21] Ritchie R. O., Nalla R. K., Kruzic J. J., and Ager J. W., Fracture and Aging in bone: Toughness and structural charateristics, J. of Material Science, vol. 42, pp. 225-232, 2006.

[22] Abdel-Wahab A. A., and Silberschmidt V. V., Numerical modelling of impact fracture of cortical bone tissue using X- FEM, J of Theoretical and Apllied Mechanics, vol. 49, pp. 599-619, 2011.

[23] Fantner G. E., Birkedal H., Kindt J. H., Hassenkam T., and Weaver J. C., Influence of the degradation of the organic matrix on the microscopic fracture behaviour of trabecular bone, J. of Bone vol. 35, pp. 1013-1022, 2004.

[24] Olszta M. J., Cheng X., Jee S. S., Kumar R., Kim Y.-Y., Kaufman M. J., Douglas E. P., and Gower L. B., Bone structure and formation : A new perspective, J. of Material Science and Engineering R, vol. 58, pp. 77-116, 2007.

[25] Rude R. K., Gruber H. E., and Norton H. J., Dietary magnesium reduction to $25 \%$ of nutrient requirement disrupts bone and mineral metabolism in the rat, J. of Bone, vol. 37, pp. 211-219, 2005.

[26] Mittra E., Rubin C., and Gruber B., Evaluation of trabecular mechanical and microstructural properties in human calcaneal bone of advanced age using mechanical testing, micro and CT DXA, J. Biomechanics, vol. 41, pp. 368-375, 2008.

[27] Burr D. B., Bone material properties and mineral matrix contributions to fracture risk or age in women and men, J. Musculoskel Neuron Interact, vol. 2, pp. 201-204, 2001

[28] Price P. A., Caputo J. M., and Williamson M. K., Bone origin of the serum complex of calcium, phosphate, fetuin, and matrix gla protein: Biochemical evidence for the cancellous bone-remodeling compartment, J. of Bone and Mineral Research, vol. 17, pp. 1171-1179, 2002.

[29] Boskey A. L. and Mendelson R., Infrared spectroscopic characterization of mineralized tissues, J. of Vibrational Spectroscopy, vol. 38, pp. 107-114, 2005.

[30] Gourion-Arsiquad S., Burket J. C., Havill L. M., DiCarlo E., Doty S. B., Mendelsohn R., Meulen M. C. H., and Boskey A. L., Spatial variation in osteonal bone properties relative to tissue and animal age, J. of Bone and Mineral Reaserch, vol. 24, pp. 12711281,2009

[31] Wehren L. E., Hawkes W. G., Hebel J. R., Orwig D. L., and Magaziner J., Bone mineral density, soft tissue body composition, strength, and functioning after hip fracture, J. of Gerontology, vol. 60, pp. 80-84, 2005.

[32] Tucker K. L., Hannan M. T., Chen H., Cupples L. A., Wilson P. W., and Kiel D. P., Potassium, magnesium, and fruit and vegetable intakes are associated with greater bone mineral density in elderly men and women, Am J. Clin Nutr, vol. 69, pp. 727-736, 1999.

[33] Ruppel M. E., Burr D. B., and Miller L. M., Chemical makeup of microdamaged bone differs from undamaged bone, J. of Bone, vol. 39, pp. 318-324, 2006 .

[34] Gamsjaeger S., Masic A., Roschger P., and Kazanci M., Cortical bone composition and orientation as a function of animal and tissue age in mice by Raman spectroscopy, J. of Bone, vol. 47, pp. 392-399, 2010. 
[35] Julkunen P., Harjula T., and Livarinen J., Biomechanical, biocchemical and structural correlations in immature and mature rabbit articular cartilage, J. of Osteoarthritis and Cartilage, vol. 17, pp. 1628-1638, 2009.

[36] Boivin G., Bala Y., Doublier A., Farlay D., Meunier P. J., and Delmas P. D., The role of mineralization and organic matrix in the microhardness of bone tissue from controls and osteoporotic patients, J. of Bone, vol. 43, pp. 532-538, 2008.

[37] Ortoft G., Mosekilde L., and Hasling C., Estimation of vertebral body strength by dual photon absorptiometry in elderly individuals: Comparison between measurements of total vertebral and vertebral body bone mineral, J. of Bone, vol. 14, pp. 667-673, 1993.

[38] Nieves J. W., Osteoporosis: The role of micronutrients, Am J. Clin Nutr, vol. 81, pp. 1232S-9S, 2005.

[39] Collins M. J., Nielsen-Marsh C. M., Hiller J., and Smith C. I., The survival of organic matter in bone: A review, J. of Archaeometry, vol. 44, pp. 383-394, 2002.

[40] Hoffler C. E., Moore K. E., and Kozloff K., Age, gender, and bone lamellae elastic moduli, J. of Orthopaedic Research, vol. 18, pp. $432-437,2000$. 